\title{
Discrete Policy Changes and Empirical Models of the Federal Funds Rate
}

\author{
Michael J. Dueker and Robert H. Rasche
}

I n macroeconomic models with monthly or quarterly data, it is common to assume that variables-such as output, investment, and inflation-respond to the monthly or quarterly average of the daily federal funds rate. The idea is that the cumulative flow of investment spending within a quarter, for example, does not depend on the value of the federal funds rate at a point in time but, instead, on its average level throughout the quarter. In fact, the use of the monthly or quarterly average of the federal funds rate is common practice in a variety of empirical macroeconomic models, from vector autoregressions (e.g., Bernanke and Blinder, 1992) to estimated versions of stochastic dynamic general equilibrium models (e.g., Lubik and Schorfheide, 2004). In addition, the daily effective federal funds rate contains noise in the form of departures from the target level set by monetary policymakers, as a result of idiosyncratic conditions in the interbank loan market on a given day. Averaging the daily rates across a month or quarter is one way to cancel most of this noise-and is yet another reason why the use of monthly and quarterly averages has become a widely used measure of monetary policy. Hence, regardless of the direction of the evolution of empirical macroeconomics, the use of the monthly or quarterly average of the daily federal funds rate will likely remain common practice.

Another feature common to otherwise disparate approaches to macroeconomic modeling is that the federal funds rate has its own equation called the policy equation. Because Federal Reserve policymakers use the federal funds rate as their policy instrument, one equation in the model describes the way that policymakers adjust the policy instrument in response to the current state of the economy. In practice, monetary policymakers adjust a target level for the federal funds rate by discrete increments at their regularly scheduled meetings or in conference calls. One often-neglected consequence of quarterly averaging is that any change in the target federal funds rate will affect the quarterly average in two different quarters. For example, if policymakers raise the target by 50 basis points precisely halfway through this quarter, then the current quarter's average will rise by 25 basis points relative to last quarter, and next quarter's average will also exceed this quarter's average by 25 basis points, all else equal. Note that this calculation relies on a key feature of target changes: They are in effect until further notice and not for a specified time period. In other words, monetary policymakers could announce a 25 -basis-point increase in the target federal funds rate that would be in effect for the next 60 days, but this is not what they do. Instead, each target change is in effect until further notice. Hence, a target change made now is likely to persist into the following quarter.

Despite this clear source of predictable change in the quarterly average of the federal funds rate, the vast bulk of the literature that estimates policy equations ignores information concerning the timing and magnitude of discrete changes to the target federal funds rate. As a result, such empirical models end up trying to predict the effect on the monthly or quarterly average of known, past policy actions rather than include this piece of data in the forecast information set. While this information about discrete target changes might seem like a second-order issue in the estimation of policy equations, we present estimates of a Taylor-type policy equation (Taylor, 1993) that suggest otherwise. It turns out that policy equations of the quarterly average of the federal funds rate that take account of discrete changes to the target federal funds rate fit the data substantially better than those that omit this information. In addition, we show that empirical results on important policy questions can be overturned, depending on whether a discreteness-adjustment

Michael J. Dueker is an assistant vice president and Robert H. Rasche is a senior vice president and director of research at the Federal Reserve Bank of St. Louis. Andrew Alberts provided research assistance.

Federal Reserve Bank of St. Louis Review, November/December 2004, 86(6), pp. 61-72

(c) 2004, The Federal Reserve Bank of St. Louis. 
term is included in the estimation of a policy equation. In particular, we focus in this paper on a debate concerning the source of interest rate smoothingan issue discussed in greater detail in the next section. Given the results in this paper, we recommend that such a discreteness-adjustment term be included as a regular feature of empirical models of the quarterly or monthly average of the federal funds rate.

\section{THE DEBATE ON INTEREST RATE SMOOTHING IN ESTIMATED POLICY EQUATIONS}

One lively debate in empirical macroeconomics is whether monetary policymakers adjust the federal funds rate gradually in response to developments in the economy or, alternatively, whether the determinants of the interest rate evolve gradually enough to account for the sluggish pace of observed changes in the interest rate. Sack (2000) and Clarida, Gali, and Gertler (2000) argue for the former; Rudebusch (2002) argues for the latter; English, Nelson, and Sack (2003) find evidence of both. This question can be summarized as follows: Do policymakers smooth the interest rate by overtly choosing to adjust it gradually? Three reasons have been put forth for rate smoothing and partial adjustment. First, policymakers are uncertain about the true structure of the economy and this source of possible policy mistakes leads them to act less forcefully in the short run (Sack, 2000). Second, and similarly, policymakers are uncertain about the accuracy of initial data releases - another source of possible policy mistakes (Orphanides, 2001). Third, and perhaps most relevant, is the idea from Woodford (2003) that monetary policymakers can influence market expectations if they show a willingness to implement-even through gradual actions-a large long-run interest rate response if necessary. For example, suppose that policymakers indicate that they are willing to raise the federal funds rate by an eventual amount of 120 basis points if a 40-basis-point increase in inflation persists. Policymakers demonstrate this willingness by embarking on a path of raising the interest rate gradually. If the public believes that this gradual path will be implemented for as long as necessary to reduce inflation, market expectations will adjust quickly, with the beneficial effect of reducing inflation without requiring much actual increase in the interest rate.

A dissenting voice to the interest rate smoothing argument is Rudebusch (2002), who suggests that episode-specific factors influence the setting of monetary policy and are not captured by simple empirical policy equations. For example, the credit crunch in the early 1990s, the financial market upset in 1998, and the terrorist attacks on September 11, 2001, all created uncertainties that had a persistent influence on the level of the federal funds rate, yet they are not incorporated in simple policy equations. Rudebusch suggests that purported evidence of interest rate smoothing is actually only a product of omitted variable bias. Since it is not really possible to include or even measure all of the relevant variables in an interest rate regression, Rudebusch (2002) concludes that the lagged policy rate (a measure of interest rate smoothing) can be included in regressions but should not be interpreted as a structural feature of monetary policy practice.

To disentangle these two competing hypotheses, English, Nelson, and Sack (2003) studied a specification for a policy rule that can nest these two interpretations of Federal Reserve policy. Their results suggest a significant role for both interpretations, although their analysis indicated that interest rate smoothing was perhaps the most important factor quantitatively. In this article, we demonstrate that empirical tests concerning this debate can be overturned if the effects of discrete target changes are taken into account. The next section describes such a discreteness adjustment.

\section{DISCRETE TARGET CHANGES AND FORECASTS OF THE QUARTERLY AVERAGE}

The discreteness adjustment is the one used in Dueker (2002) and assumes that any target change made to the federal funds rate during the quarter is likely to remain in force through the next quarter. In this case, the starting point for this quarter's funds rate is not the previous quarter's average but the target rate that held at the end of the previous quarter. Another way to look at this issue is to note that, if a quarter has $N$ business days and a 50-basis-point increase in the target federal funds rate occurs after $N_{j}$ business days have elapsed in the quarter, then, other things equal, the effect of such a target change on the next quarter's average, relative to this quarter's average, would be to increase it by $N_{j} / N \times 50$ basis points above this quarter's average, $i_{t}$. If more than one discrete change takes place within a quarter, then the effect of the target changes on the quarterly average would be 


\section{Figure 1}

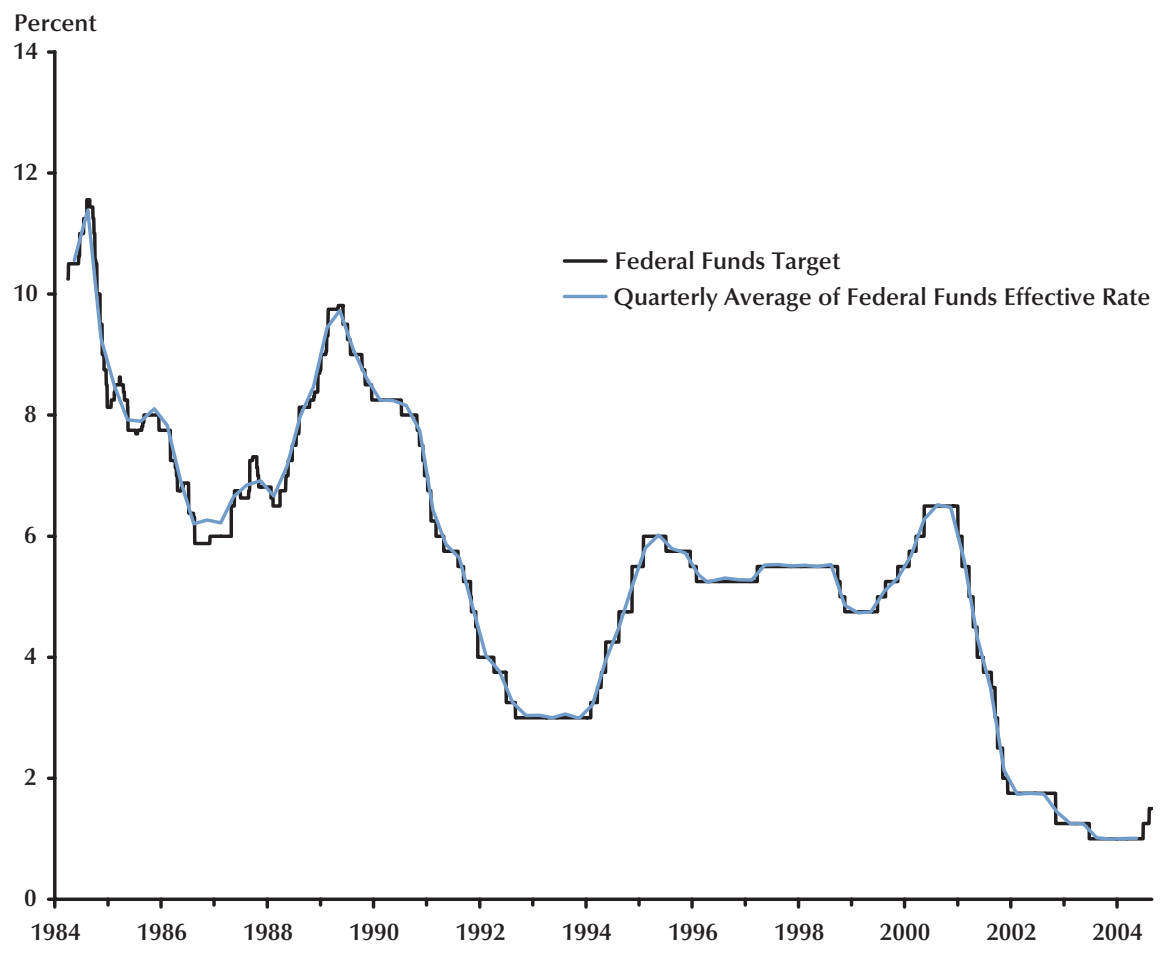

\section{Figure 2}

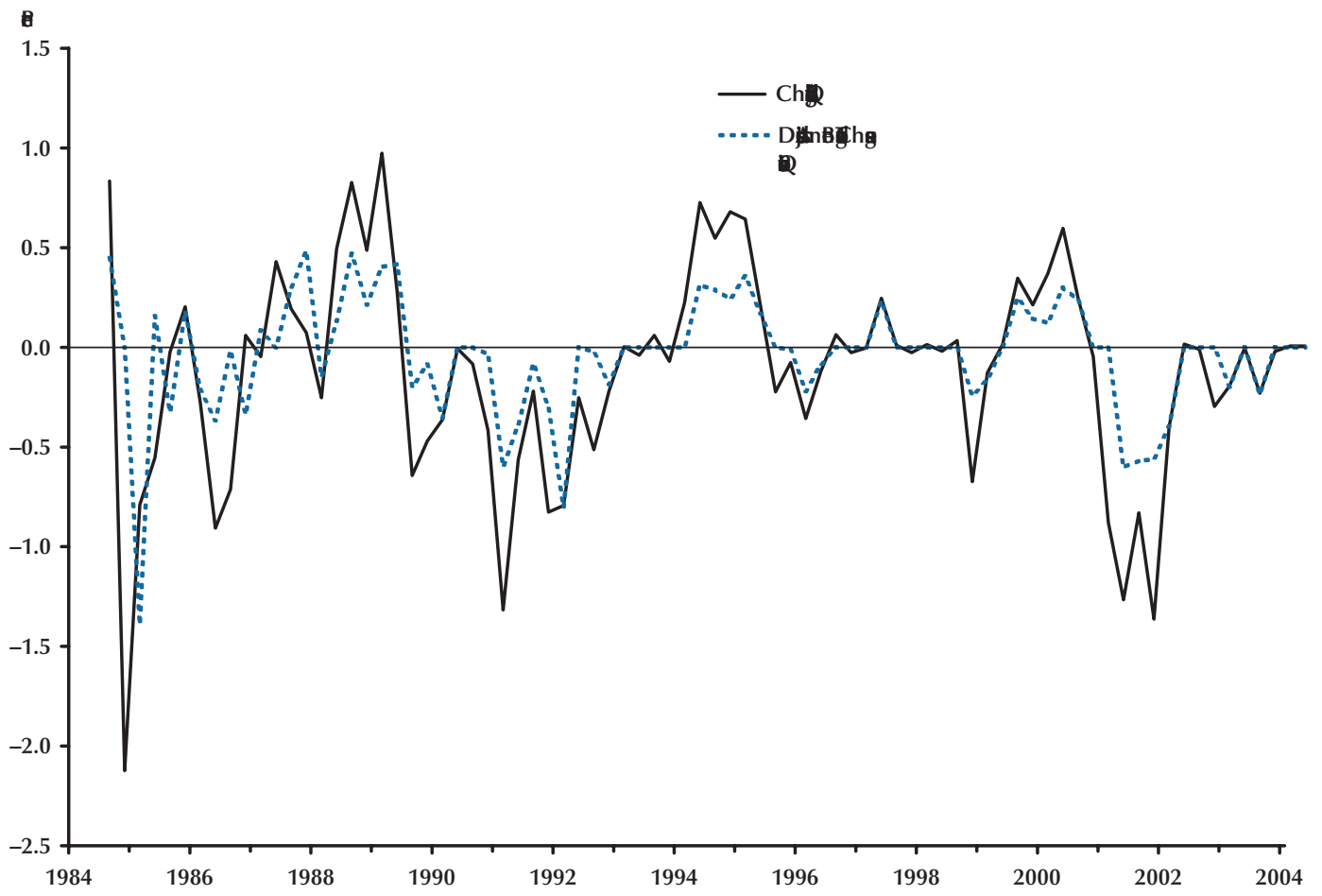




$$
D D V_{t-1}=\sum_{j} N_{j} / N \times \Delta i_{j, t-1}^{T},
$$

where the discrete target changes are denoted $\Delta i^{T}$ and $D D V$ is the discreteness variable first used in Dueker (2002). An equivalent way to present this discreteness adjustment is that it serves as a link between last quarter's average and the target rate at the end of the quarter:

$$
i_{t-1}+D D V_{t-1}=i_{t-1}^{T}
$$

where $i^{T}$ is the end-of-period value of the target federal funds rate and $i$ is the quarterly average.

Figure 1 plots the target federal funds rate along with the quarterly average of the federal funds rate. In the chart, one can see that target changes can precede some upward and downward shifts in the quarterly average. Figure 2 makes this pattern even more apparent: It plots the changes in the quarterly average, $i_{t}-i_{t-1}$, with the discreteness adjustment, $D D V_{t-1}=i_{t-1}^{T}-i_{t-1}$. It is clear from the close correspondence in Figure 2 that $D D V_{t-1}$ will be a relatively powerful predictor of changes in the quarterly average of the federal funds rate, based on target changes that took place in the previous quarter. Indeed this conjecture proves to be the case in the empirical results presented in the next section.

\section{ESTIMATION RESULTS FOR LINEAR TAYLOR RULES WITH RATE SMOOTHING}

English, Nelson, and Sack (2003) observed that the hypotheses of interest rate smoothing and persistent omitted factors can be nested in one specification of a policy equation. Using their notation, let $i, \pi$, and $y$ denote, respectively, the interest rate, the inflation rate, and the output gap. As discussed above, the interest rate used as the monetary policy instrument is the quarterly average of the federal funds rate; the inflation rate is the most recent fourquarter change in the chain-weighted personal consumption expenditures price index; the output gap is the percentage difference between chainweighted real gross domestic product (GDP) and the potential GDP measure from the Congressional Budget Office. The sample period is from 1984:Q2 to 2004:Q2 and coincides with the period for which a well-accepted series for the target federal funds rate exists.

For this illustration of the effects of discrete target changes on the quarterly average of the federal funds rate, the basic policy equation is a contemporaneous
Taylor rule, whereby monetary policy responds to the current values of the inflation rate and the output gap. (Alternative forward-looking Taylor rules can make use of measures of expected inflation.) With the two behavioral assumptions appended, the following three equations describe the policy rule in its entirety:

$$
\begin{array}{ll}
\hat{i}_{t}=b_{0}+b_{\pi} \pi_{t}+b_{y} y_{t} & \text { Taylor rule } \\
\text { (3) } i_{t}=(1-\lambda) \hat{i}_{t}+\lambda i_{t-1}+v_{t} & \text { Rate smoothing } \\
v_{t}=\rho v_{t-1}+\varepsilon_{t}, & \text { Autogressive errors }
\end{array}
$$

where $\hat{i}$ represents the Taylor rule-implied level of the federal funds rate in the absence of interest rate smoothing and policy concerns other than inflation and the output gap; $\lambda$ is the interest rate smoothing parameter under the assumption that the rate policymakers inherit from the past is $i_{t-1}$ (which we can also call the reference rate for the purposes of interest rate smoothing); and $\rho$ measures the persistence of omitted factors that also concern monetary policymakers. For the side of the debate that believes that monetary policymakers smooth interest rates purposefully, $\lambda$ would account for the gradual adjustment of the federal funds rate and $\rho$ would be zero. For the opposite side of the debate, $\lambda$ would be zero and the gradual adjustment would be explained by errors due to omitted ancillary policy concerns, such as financial market disturbances, in the form of autoregressive model errors.

The purpose of the interest rate smoothing equation is to assume that monetary policymakers set the rate this period equal to a weighted average of the rate implied by the Taylor rule and the rate inherited from the previous quarter. Following the previous period's target changes, however, the rate inherited from the past ought to be the end-of-period target level, $i_{t-1}^{T}$, and not $i_{t-1}$, the previous quarter's average. But this hypothesis is testable, as we can nest the two specifications as follows.

With discreteness adjustment, the expression in equation (3) becomes

(4)

$$
\begin{aligned}
& \hat{i}_{t}=b_{0}+b_{\pi} \pi_{t}+b_{y} y_{t} \quad \text { Taylor rule } \\
& \begin{aligned}
& i_{t}=(1-\lambda) \hat{i}_{t}+\lambda\left[i_{t-1}+D D V_{t-1}\right]+\delta D D V_{t-1}+v_{t} \\
& \text { Discreteness-adjusted rate smoothing }
\end{aligned} \\
& v_{t}=\rho v_{t-1}+\varepsilon_{t}, \quad \text { Autoregressive errors }
\end{aligned}
$$




\section{Table 1}

\section{Calculation of the Discreteness Adjustment}

\begin{tabular}{|c|c|c|c|c|c|c|c|}
\hline \multirow{2}{*}{$\begin{array}{l}\text { D } \\
\text { 1990:Q4 } \\
\text { Rate change }\end{array}$} & \multicolumn{2}{|c|}{ Days in quarter } & \multicolumn{3}{|c|}{ Days within quarter when target changed } & \multicolumn{2}{|c|}{$\begin{array}{l}\text { Discreteness adjustment } \\
\text { for following quarter }\end{array}$} \\
\hline & 66 & $\begin{array}{c}12 \\
-0.25 \\
(20 / 66)^{*}(-0.25)\end{array}$ & $\begin{array}{c}33 \\
-0.25 \\
+\quad(32 / 66) *(-0.25)\end{array}$ & $\begin{array}{c}50 \\
-0.25 \\
+(49 / 66) *(-0.25)\end{array}$ & $\begin{array}{c}58 \\
-0.25 \\
+\quad(57 / 66) *(-0.25)\end{array}$ & $=$ & -0.5985 \\
\hline $\begin{array}{l}\text { 1994: Q2 } \\
\text { Rate change }\end{array}$ & 65 & $\begin{array}{c}12 \\
0.25 \\
(11 / 65)^{*}(0.25)\end{array}$ & $\begin{array}{c}33 \\
0.50 \\
+\quad(32 / 65)^{*}(0.50)\end{array}$ & - & - & $=$ & 0.2885 \\
\hline $\begin{array}{l}\text { 2001: Q1 } \\
\text { Rate change }\end{array}$ & 65 & $\begin{array}{c}3 \\
-0.50 \\
(2 / 65) *(-0.50)\end{array}$ & $\begin{array}{c}23 \\
-0.50 \\
+\quad(22 / 65)^{*}(-0.50)\end{array}$ & $\begin{array}{c}57 \\
-0.50 \\
+\quad(56 / 65) *(-0.50)\end{array}$ & - & $=$ & -0.6154 \\
\hline
\end{tabular}

where the rate inherited from the previous quarter is the end-of-period target level, $i_{t-1}^{T}=i_{t-1}+D D V_{t-1}$, if $\delta=0$ and it equals the previous quarter's average if $\delta=-\lambda$.

English, Nelson, and Sack (2003) combine the three expressions from equation (3) into one equation that describes the changes in the federal funds rate:

(5)

$$
\begin{aligned}
& \Delta i_{t}=(1-\lambda) \Delta \hat{i}_{t}+\lambda \Delta i_{t-1}+(\rho-1)\left[i_{t-1}-(1-\lambda) \hat{i}_{t-1}-\lambda i_{t-2}\right]+\varepsilon_{t} \\
& \varepsilon_{t} \sim N\left(0, \sigma^{2}\right),
\end{aligned}
$$

where $\hat{i}$ is the Taylor rule-implied level of the federal funds rate absent any interest rate smoothing or autoregressive errors due to ancillary policy concerns.

With the discreteness adjustment, the combined expression is as follows:

(6)

$$
\begin{aligned}
& \Delta i_{t}=(1-\lambda) \Delta \hat{i}_{t}+\lambda \Delta i_{t-1}+(\lambda+\delta) \Delta D D V_{t-1} \\
& +(\rho-1)\left[i_{t-1}-(1-\lambda) \hat{i}_{t-1}-\lambda i_{t-2}-(\lambda+\delta) D D V_{t-2}\right]+\varepsilon_{t}
\end{aligned}
$$

A key feature of the specification in equations (5) and (6) is that it does not impose either hypothesis $(\lambda=0$ or $\rho=0)$. Judd and Rudebusch (1998) called $\Delta i_{t-1}$ a term that captured "momentum" from the previous period's funds rate change. The purpose of the discreteness adjustment, however, is to provide an accurate reflection of the momentum implied by the previous period's discrete target changes, which frees $\Delta i_{t-1}$ from having to play this role.

Nonlinear least-squares estimates for equation (5) are shown in the first column of Table 2. The results without the discreteness adjustment, $D D V$, concur with English, Nelson, and Sack (2003) in that both $\lambda$ and $\rho$ are significantly greater than zero, and the Taylor rule still seems operative, given significant coefficients on $b_{\pi}$ and $b_{y}$. A well-known stability property of Taylor rules is that the coefficient on inflation must be greater than 1 and the estimate of $b_{\pi}=1.25$ from equation (5) meets this criterion even if its standard error is 0.50. In most cases, the analysis often stops at this point, with a standard error of the regression of 33 basis points per quarter.

Our discussion of the discreteness adjustment leads us to believe, however, that these results might change if the empirical model incorporated information regarding target changes in the previous quarter. Equation (4) suggests that when $\delta=0$, the starting point for interest rate smoothing is the endof-period target rate, rather than the most recent quarterly average. If it is the quarterly average, on the other hand, then a value of $\delta=-\lambda$ would remove the discreteness adjustment, $D D V$, from equations (4) and (6). The second column of Table 2 shows estimates of equation (6) with an estimate of $\delta$. Put in the context of equation (2), this value of $\delta$ implies that the reference rate for interest smoothing is $i_{t-1}+1.24\left(i_{t-1}^{T}-i_{t-1}\right)$. This coefficient is very close to the value of 1.21 that Dueker (2002) found on the same discreteness-adjustment variable in a vector autoregression. In both cases, however, the coefficient $\delta$ is not significantly different from zero, which suggests that the reference rate for interest rate smoothing is the end-of-period target rate, $i_{t-1}^{T}$, and not the most recent quarterly average, $t_{t-1}$. Accordingly, the last column in Table 2 shows the estimates for equation (6) with $\delta$ set to zero and finds that the standard error of the regression is essentially unchanged from when $\delta=0.24$ (middle column of 


\section{Table 2}

Taylor Rule Policy Equations with and without Discreteness Adjustment, 1984:Q2-2004:Q2

\begin{tabular}{|c|c|c|c|c|}
\hline Variable & Coefficient & No discreteness & & \\
\hline Intercept & $b_{0}$ & $\begin{array}{c}2.28 \\
(1.24)\end{array}$ & $\begin{array}{c}1.12 \\
(2.42)\end{array}$ & $\begin{array}{c}1.24 \\
(1.85)\end{array}$ \\
\hline Inflation & $b_{\pi}$ & $\begin{array}{c}1.248 \\
(0.498)\end{array}$ & $\begin{array}{c}1.971 \\
(0.937)\end{array}$ & $\begin{array}{c}1.846 \\
(0.706)\end{array}$ \\
\hline Output gap & $b_{y}$ & $\begin{array}{c}0.853 \\
(0.354)\end{array}$ & $\begin{array}{c}0.948 \\
(0.610)\end{array}$ & $\begin{array}{c}1.073 \\
(0.486)\end{array}$ \\
\hline Rate smoothing & $\lambda$ & $\begin{array}{c}0.719 \\
(0.108)\end{array}$ & $\begin{array}{c}0.951 \\
(0.035)\end{array}$ & $\begin{array}{c}0.919 \\
(0.041)\end{array}$ \\
\hline Autoregressive errors & $\rho$ & $\begin{array}{c}0.769 \\
(0.134)\end{array}$ & $\begin{array}{c}0.281 \\
(0.144)\end{array}$ & $\begin{array}{c}0.438 \\
(0.118)\end{array}$ \\
\hline Inherited rate & $\delta$ & - & $\begin{array}{c}0.241 \\
(0.182)\end{array}$ & - \\
\hline $\begin{array}{l}\text { S.E.E. } \\
\bar{R}^{2}\end{array}$ & $\sigma$ & $\begin{array}{l}0.333 \\
0.502\end{array}$ & $\begin{array}{l}0.275 \\
0.660\end{array}$ & $\begin{array}{l}0.275 \\
0.660\end{array}$ \\
\hline
\end{tabular}

NOTE: Standard errors are in parentheses.

Table 2). In contrast, the standard error of the regression in Table 2 is 21 percent higher when the discreteness adjustment is omitted. Based on this estimate, we set $\delta=0$ in all subsequent model specifications.

In terms of Taylor rule coefficients, interest rate smoothing parameters, and autoregressive errors, the estimates with and without the discreteness adjustment are also different. The point estimates of the inflation and output gap response coefficients are higher with the discreteness adjustment, although their standard errors are relatively large. In the last column of Table 2 , the estimated values of $b_{\pi}$ and $b_{y}$ are 1.85 and 1.07 , respectively. In addition, the estimated value of $\lambda$ goes up and $\rho$ goes down with the discreteness adjustment. Instead of being roughly equal at about 0.75 without the discreteness adjustment, $\lambda=0.92$ and $\rho=0.44$ with the discreteness adjustment (last column of Table 2).

Two caveats, however, hinder us from interpreting $\lambda=0.92$ as direct evidence of interest rate smoothing. First, this estimate covers all quarters and thereby mixes the roughly 40 percent of all quarters when the target federal funds rate did not change with the 60 percent when the target did change. Second, we need to consider the fact that monetary policymakers would not move the target funds rate to the Taylor rule-implied level at the beginning of each quarter; instead they could act slowly but, by the end of the period, set the target rate, $i^{T}$, equal to the Taylor rate, $\hat{i}$. As an extreme example, suppose that the target is always unchanged until two-thirds of the way through each quarter, whereupon it is set equal to the Taylor rate, $\hat{i}$. This timing alone would result in a value of $\lambda=0.66$ to match the quarterly average:

$$
i_{t}=0.333 \hat{i}_{t}+0.667 i_{t-1}^{T} \text {. }
$$

Firm evidence of interest rate smoothing requires that $\hat{i}_{t}-i_{t}^{T}$ show persistence beyond any found in the autoregressive errors. To study the persistence of $\hat{i}_{t}-i_{t}^{T}$, however, we would like the estimate of $\hat{i}_{t}$ to come from a model that recognizes that policymakers do not change the target funds rate every quarter and, hence, the standard deviation of the residual, denoted $\sigma$, will sometimes be much lower than the 28 basis points shown in Table 2 .

One way to separate the target change/no target change regimes in a predictive model is to make $\lambda$ and the standard deviation, $\sigma$, subject to regime switching. We explore such a nonlinear Taylor rule model of monetary policy in the next section.

\section{ESTIMATION RESULTS FOR NONLINEAR TAYLOR RULES WITH RATE SMOOTHING}

A clean test for interest rate smoothing - in the form of persistence in the gap between the Taylor rule rate and the end-of-period target, $\hat{i}_{t}-i_{t}^{T}$-would 


\section{Table 3}

\section{Markov-Switching Model with Switching in Taylor Rule Intercept and Smoothing, 1984:Q2-2004:Q2}

\begin{tabular}{lccc} 
Variable & Coefficient & No discreteness & Discreteness \\
\hline Intercepts & $b_{0, S 1=1}$ & -0.898 & 0.581 \\
& & $(0.819)$ & $(0.421)$ \\
& $b_{0, S 1=2}$ & 2.48 & 4.35 \\
& & $(0.657)$ & $(0.480)$ \\
Inflation & $b_{\pi}$ & 1.927 & 1.721 \\
& & $(0.239)$ & $(0.167)$ \\
Output gap & $b_{y}$ & 0.969 & 1.11 \\
& & $(0.164)$ & $(0.094)$ \\
Rate smoothing & $\lambda_{S 2=1}$ & 1.0 & 0.980 \\
& & & $(0.003)$ \\
Rate smoothing & $\lambda_{S 2=2}$ & 0.717 & 0.888 \\
& & $(0.045)$ & $(0.033)$ \\
Autoregressive errors & $\rho$ & 0.280 & 0.00 \\
& & $(0.030)$ & $(0.012)$ \\
Transition probabilities & $p_{1}$ & 0.955 & 0.947 \\
& & $(0.034)$ & $(0.043)$ \\
Transition probabilities & $q_{1}$ & 0.951 & 0.943 \\
& & $(0.038)$ & $(0.049)$ \\
Transition probabilities & $p_{2}$ & 0.473 & 0.636 \\
& & $(0.137)$ & $(0.122)$ \\
Transition probabilities & $q_{2}$ & 0.711 & 0.763 \\
& & $(0.087)$ & $(0.077)$ \\
S.E.E. & $\sigma_{S 2=1}$ & 0.057 & 0.014 \\
& & $(0.010)$ & $(0.004)$ \\
S.E.E. & $\sigma_{S 2=2}$ & 0.271 & 0.303 \\
& & $(0.030)$ & $(0.042)$ \\
& & &
\end{tabular}

NOTE: Standard errors are in parentheses.

use an estimate of the Taylor rule rate from a model that had two key attributes: First, the model would not use data from quarters when policymakers did not change the target federal funds rate to estimate Taylor rule coefficients; second, the model would not have autocorrelated errors. The first attribute is important because we want a model that fits the data in quarters where the target does not change with the common-sense specification, $\Delta i_{t}=D D V_{t-1}=$ $i_{t-1}^{T}-i_{t-1}$, which requires in equation (6) that $\lambda=1$, $\rho=0$, and $\delta=0$ for those non-target-change observations. If the second attribute, $\rho=0$, holds for all observations, then the end-of-period target ought to equal the Taylor rule rate under the hypothesis of no rate smoothing.
To find a model specification that has these two desirable attributes, we introduce Markov switching to two of the model parameters, $\lambda$ and $b_{0}$, the Taylor rule intercept. The intent is to allow complete smoothing $\left(\lambda_{1} \approx 1\right)$ in one of the states, which ought to coincide fairly well with the periods when the target does not change. The value of $\lambda$ in the other state, $\lambda_{2}$, could take on a lower value. The objective behind regime switching in the Taylor rule intercept, $b_{0}$, is to lower or eliminate autocorrelation in the model errors. In a Taylor rule, the intercept $b_{0}=r^{*}-$ $\left(1-b_{\pi}\right) \pi^{*}$, where $r^{*}$ is the equilibrium short-term real interest rate and $\pi^{*}$ is the inflation target. Because temporary changes in some combination of $r^{*}$ and $\pi^{*}$ could occur across the business cycle or in periods 


\section{Figure 3}

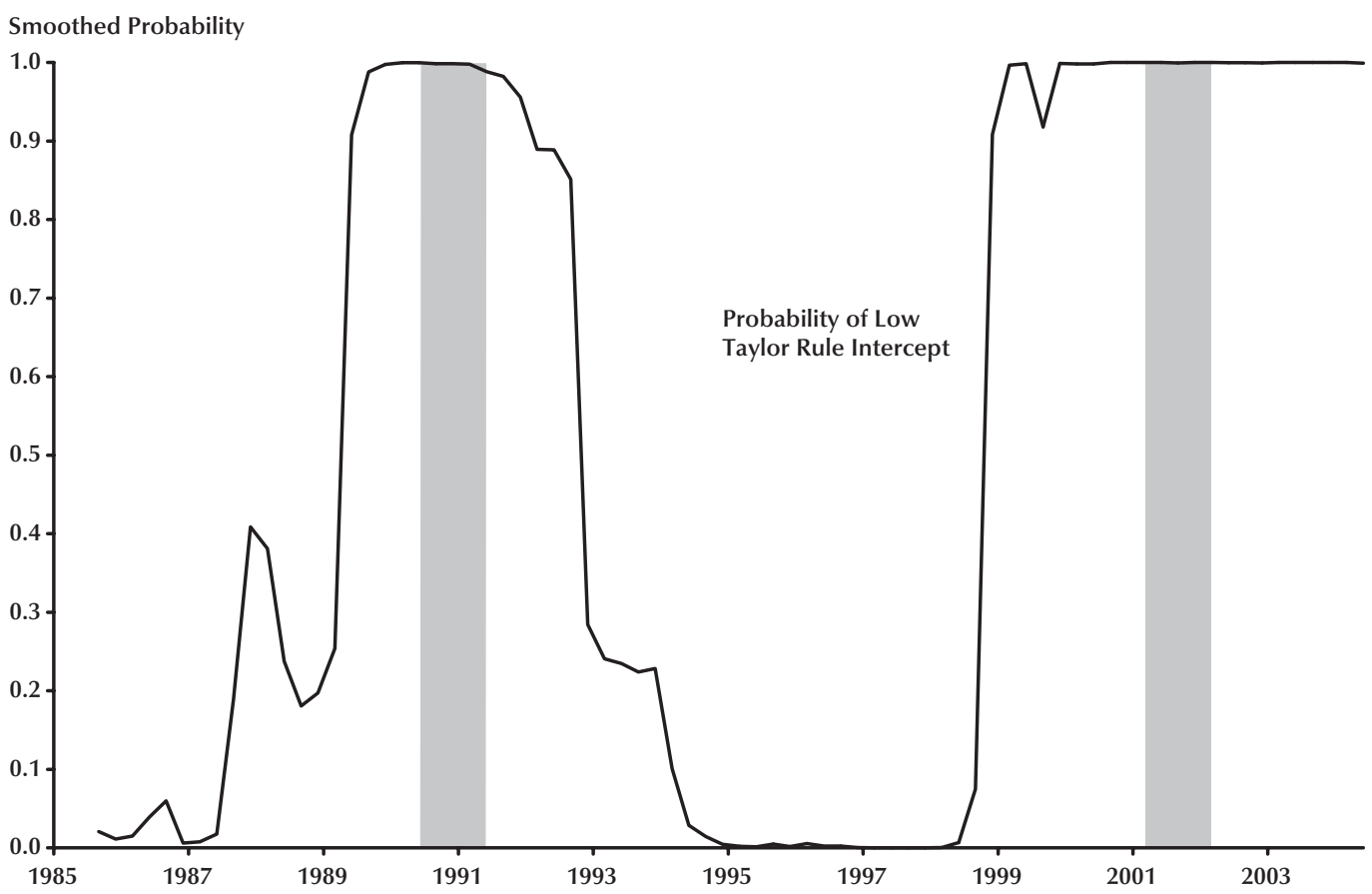

NOTE: Shaded areas are recessions (as determined by the National Bureau of Economic Research).

of financial market upset, it seems natural to investigate whether variation in $b_{0}$ could remove some or all of the autocorrelation in the errors.

We allow the regime switching in these two parameters to take place independently through two separate state variables, $S 1$ and $S 2$. Thus, the Taylor rule rate with regime switching is

$$
\hat{i}_{t}=b_{0, S 1_{t}}+b_{\pi} \pi_{t}+b_{y} y_{t}, \quad \text { Taylor rule }
$$

where $S 1_{t}=1,2$ is an unobserved state variable and the transition probabilities are denoted

$p_{1}=\operatorname{Pr}\left(S 1_{t}=1 \mid S 1_{t-1}=1\right)$ and $q_{1}=\operatorname{Pr}\left(S 1_{t}=2 \mid S 1_{t-1}=2\right)$.

The rate-smoothing equation with regime switching is

$$
i_{t}=\left(1-\lambda_{S 2_{t}}\right) \hat{i}_{t}+\lambda_{S 2_{t}}\left(i_{t-1}+D D V_{t-1}\right)+\sigma_{S 2_{t}} e_{t},
$$

where we also allow the variance to depend on the state variable because we expect much lower variance in the state where $\lambda \approx 1$. For the second state variable, $S 2$, we report parameter estimates for both fixed transition probabilities and time-varying transition probabilities. The fixed transition probabilities are denoted $p_{2}=\operatorname{Pr}\left(S 2_{t}=1 \mid S 2_{t-1}=1\right)$ and $q_{2}=\operatorname{Pr}\left(S 2_{t}=2 \mid S 2_{t-1}=2\right)$.

Parameter estimates for the model with fixed transition probabilities are in Table 3. Figure 3 shows the smoothed probability of the low Taylor rule intercept $(S 1=1)$ from the model with the discreteness adjustment. The periods when the Taylor rule intercept is low coincide roughly with periods when interest rates experience cyclical fluctuations around recessions, which are shaded in the chart. Importantly, the model with the discreteness adjustment is able to separate periods when the target changed from periods when it did not, because the variance parameters are farther apart for that model. The model with the discreteness adjustment is also able to eliminate the autocorrelation in the errors, whereas the model without the discreteness adjustment still has significantly autocorrelated errors, with $\rho=0.28$. Without constraining $\lambda$, it takes a value very close to 1.0 when $S 2=1$. Even when it equals 0.98 in the model with the discreteness adjustment, the economic effect of this difference in terms of basis points is negligible. In other words, the model imputes essentially zero input from the Taylor rule rate when $\lambda=0.98$.

Figure 4 shows how well the smoothed probability of $S 2=1$ matches periods when the target federal funds rate did not change for the model with the discreteness adjustment and the parameter values 


\section{Figure 4}

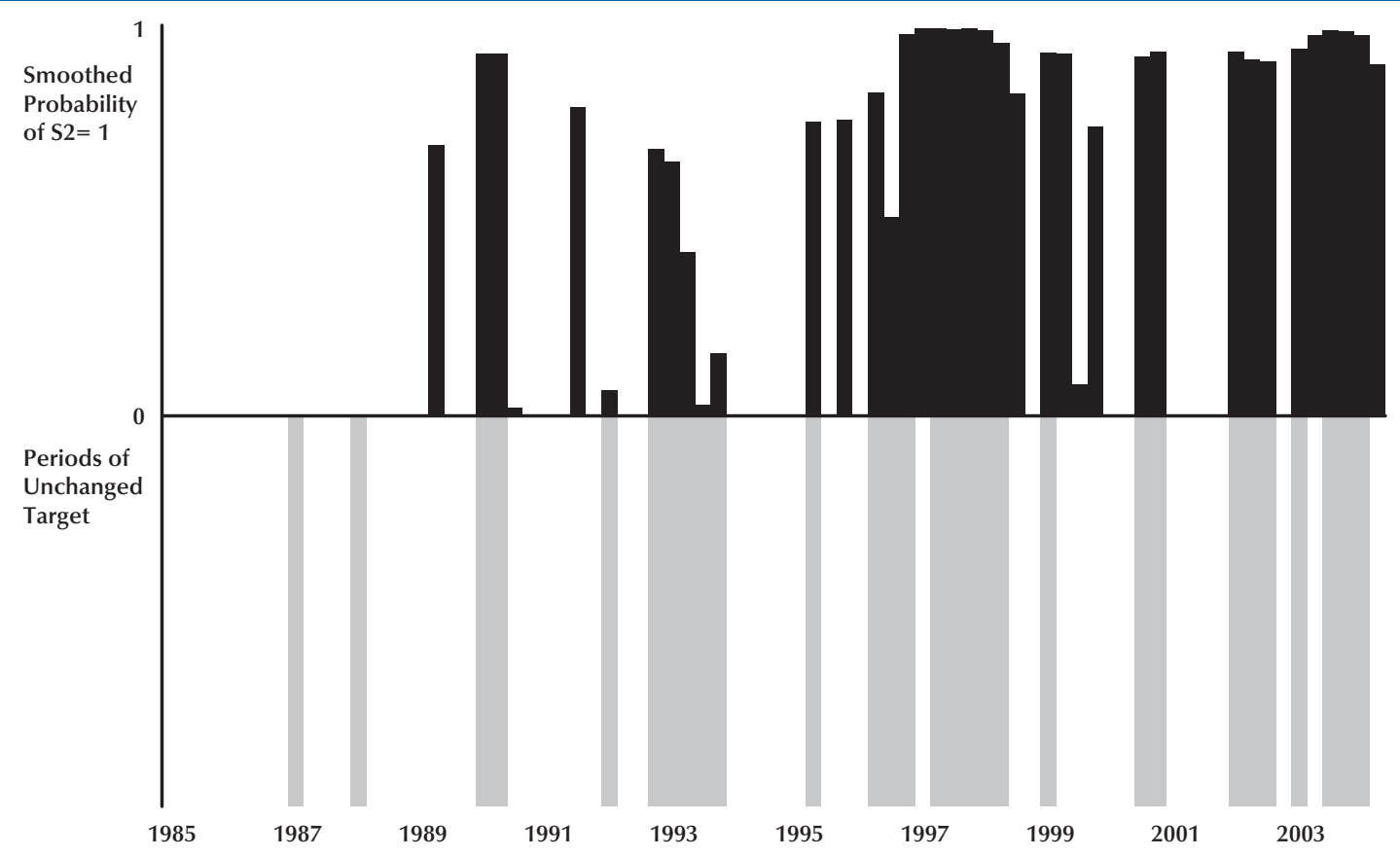

from Table 3. The correspondence is quite close, suggesting that the Taylor response coefficients are not attempting to explain much about the quarters when policymakers left the target rate unchanged, because $\lambda$ is very close to 1.0 in that state.

Despite these apparently strong results, constant transition probabilities are not completely satisfactory for switching in the parameter $\lambda$. We would expect that policymakers would respond systematically to economic developments when deciding in which periods to leave the target unchanged and set $\lambda$ to 1 . In reality, these no-change periods have an endogenous component and are not solely the result of coin flips. One natural variable to use to predict whether a target change will occur is $Z_{t}=a b s\left(\hat{i}_{t}-i_{t-1}^{T}\right)$, the gap between the Taylor rule rate and the most recent end-of-period target federal funds rate. If the size of this gap is large in absolute value, then we would expect that a target change and the regime where $\lambda \approx 1$ are more likely. With this explanatory variable, we parameterize the time-varying transition probabilities for $S 2$ as

(9)

$$
\begin{aligned}
& \operatorname{Pr}\left(S 2_{t}=1 \mid S 2_{t-1}=1\right)=\exp \left(c_{0}+c_{1} Z_{t}\right) /\left[1+\exp \left(c_{0}+c_{1} Z_{t}\right)\right] \\
& \operatorname{Pr}\left(S 2_{t}=2 \mid S 2_{t-1}=2\right)=\exp \left(d_{0}+d_{1} Z_{t}\right) /\left[1+\exp \left(d_{0}+d_{1} Z_{t}\right)\right]
\end{aligned}
$$

Because $S 2=1$ is the state where $\lambda \approx 1$ and the tar- get is less likely to change, we would expect to find $c_{1}<0$ and $d_{1}>0$. These signs would mean that monetary policymakers are more likely to accept feedback from the Taylor rule rate when the gap between the Taylor rule rate and the prevailing target rate, $\operatorname{abs}\left(\hat{i}_{t}-i_{t-1}^{T}\right)$, is large.

Parameter estimates for the Markov-switching model with time-varying transition probabilities are in Table 4. The estimates are relatively unchanged from Table 3 . The only significant coefficient on $Z_{t}$ is $c_{1}<0$ in the model without the discreteness adjustment. This coefficient implies that, if $a b s\left(\hat{i}_{t}-i_{t-1}^{T}\right)$ is large, then policymakers are likely to switch out of the state where $\lambda \approx 1$ if they had been in that state. In the model with the discreteness adjustment, $d_{1}$ has a point estimate above zero, as expected, but it is not statistically significant. Thus, although we have presented a framework for predicting when monetary policymakers are likely to keep the federal funds target unchanged, we have not yet identified a significant explanatory variable for the time-varying transition probabilities. For this reason, we report estimates from the fixed transition probability model to examine persistence in the gap between the Taylor rule rate and the end-of-period federal funds target rate, $\hat{i}_{t}-i_{t}^{T}$. Because these regimes are endogenous, further research on the process governing target rate changes is needed. In this vein, 


\section{Table 4}

Markov-Switching Model with Time-Varying Transition Probabilities on the Smoothing Parameter, 1984:Q2-2004:Q2

\begin{tabular}{lccc} 
Variable & Coefficient & No discreteness & Discreteness \\
\hline Intercepts & $b_{0, S 1=1}$ & -0.818 & 0.579 \\
& & $(1.17)$ & $(0.393)$ \\
& $b_{0, S 1=2}$ & 2.46 & 4.91 \\
& & $(0.488)$ & $(0.697)$ \\
Inflation & $b_{\pi}$ & 1.877 & 1.728 \\
& & $(0.276)$ & $(0.161)$ \\
Output gap & $b_{y}$ & 1.049 & 1.070 \\
& & $(0.244)$ & $(0.092)$ \\
Rate smoothing & $\lambda_{S 2=1}$ & 0.999 & 0.986 \\
& & $(0.008)$ & $(0.003)$ \\
Rate smoothing & $\lambda_{S 2=2}$ & 0.738 & 0.890 \\
& & $(0.070)$ & $(0.023)$ \\
Autoregressive errors & $\rho$ & 0.294 & 0.006 \\
& & $(0.026)$ & $(0.010)$ \\
Transition probabilities & $p_{1}$ & 0.974 & 0.943 \\
& & $(0.023)$ & $(0.035)$ \\
Transition probabilities & $q_{1}$ & 0.933 & 0.835 \\
& & $(0.025)$ & $(0.107)$ \\
Transition probabilities & $c_{0}$ & 433.8 & 0.261 \\
& & $(75.7)$ & $(1.00)$ \\
Transition probabilities & $c_{1}$ & -548.8 & 0.355 \\
Transition probabilities & $d_{0}$ & $(145.6)$ & $(0.633)$ \\
Transition probabilities & & 1.11 & 0.427 \\
& $d_{1}$ & $(1.00)$ & $(0.819)$ \\
S.E.E. & & -0.26 & 1.236 \\
S.E.E. & $\sigma$ & $(0.77)$ & $(1.144)$ \\
& & 0.195 & 0.245 \\
& $\sigma_{S 2=1}$ & $(0.018)$ & $(0.070)$ \\
& & 0.052 & 0.267 \\
& & $(0.009)$ & $(0.029)$ \\
& & &
\end{tabular}

NOTE: Standard errors are in parentheses.

Hamilton and Jorda (2002) present an autoregressive conditional hazard model of the target federal funds rate. Similarly, a dynamic ordered probit model, of the type that Dueker (1999) estimated, of changes in the bank prime rate could be applied to target changes.

\section{A MEASURE OF INTEREST RATE SMOOTHING}

As discussed above, only models in which the errors are not autocorrelated, $\rho=0$, imply that the end-of-period target ought to equal the Taylor rule rate under the hypothesis of no rate smoothing. A comparison of Tables 2, 3, and 4 shows that only the Markov-switching models with the discreteness adjustment eliminate the autocorrelation in the model errors. Consequently, a direct measure of the degree of interest rate smoothing is the correlogram of $\hat{i}_{t}-i_{t}^{T}$ from these two models.

However, because the value of the likelihood function barely changes between Tables 3 and 4 for the model with the discreteness adjustment, we 


\section{Figure 5}

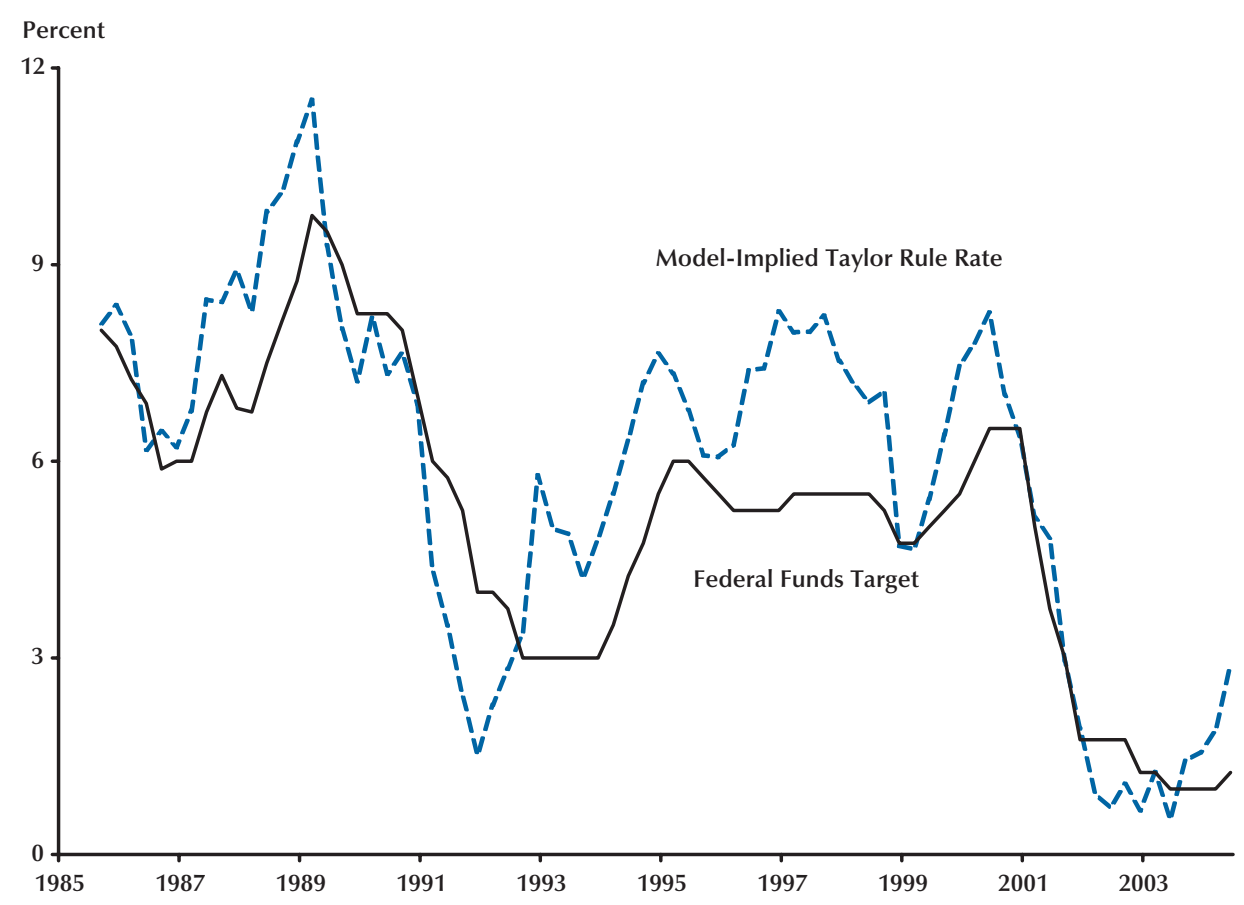

concentrate on the results from Table 3, the specification with fixed transition probabilities. Figure 5 shows the Taylor rule rate implied by the Table 4 estimates with the end-of-period target. In general, the Taylor rule rate leads the target when the target rises and falls. It is remarkable, therefore, that the target, on its descent between 2001 and 2003, did not lag the Taylor rule rate. Monetary policymakers apparently were not smoothing the interest rate as the economy went into recession in 2001. Table 5's correlogram of the difference between the modelimplied Taylor rule rate and the target federal funds rate shows that Federal Reserve policymakers close the gap within about six quarters on average. Thus, the degree of interest rate smoothing is considerable but has a relatively short horizon.

\section{SUMMARY AND CONCLUSIONS}

This article points out that discrete changes to the target federal funds rate are a clear source of predictable change in the monthly or quarterly average of the daily federal funds rates. Figure 2 suggests that the adjustment for the discrete target changes accounts for what is perhaps a surprising amount of the sample variance of the changes in the quarterly average. Thus, the discreteness adjust-

\section{Table 5}

\section{Correlogram of the Gap Between the Federal Funds Target Rate and the Markov-Switching Taylor Rule Rate with Discreteness Adjustment, 1984:Q2-2004:Q2}

\begin{tabular}{lc} 
Lag & Autocorrelation \\
\hline 1 & 0.826 \\
2 & 0.655 \\
3 & 0.447 \\
4 & 0.269 \\
5 & 0.167 \\
6 & 0.079 \\
7 & 0.054 \\
8 & -0.036 \\
9 & -0.114 \\
10 & -0.188 \\
\hline
\end{tabular}

ment carries the potential to overturn estimation results that involve the monthly or quarterly average of the federal funds rate. We present such an example by examining the debate concerning interest rate smoothing in policy rules. Without the discreteness 
adjustment, estimation results suggest that interest rate smoothing is not the only source of gradualism in interest rate changes. With the discreteness adjustment, however, the empirical results strongly favor interest rate smoothing as the source of gradualism in federal funds rate changes. We also show that the discreteness adjustment affects empirical results concerning the policy equations even in relatively rich models that include regime switching.

The Markov-switching framework we present is adept at separating the regime where policymakers change the target from the regime where they do not. This framework can employ explanatory variables in the transition probabilities to predict these regimes ahead of time. Future work can concentrate on studying the determinants of the target change decisions of policymakers.

\section{REFERENCES}

Bernanke, Ben S. and Blinder, Alan S. "The Federal Funds Rate and the Channels of Monetary Transmission." American Economic Review, September 1992, 82(4), pp. 901-21.

Clarida, Richard; Galí, Jordi and Gertler, Mark. "Monetary Policy Rules and Macroeconomic Stability: Evidence and Some Theory." Quarterly Journal of Economics, February 2000, 115(1), pp. 147-80.

Dueker, Michael J. “The Monetary Policy Innovation Paradox in VARs: A 'Discrete' Explanation.” Federal Reserve Bank of St. Louis Review, March/April 2002, 84(2), pp. 43-49.

Dueker, Michael J. "Conditional Heteroscedasticity in Qualitative Response Models of Time Series: A GibbsSampling Approach to the Bank Prime Rate." Journal of Business and Economic Statistics, October 1999, 17(4), pp. 466-72.
English, William B.; Nelson, William R. and Sack, Brian P. "Interpreting the Significance of the Lagged Interest Rate in Estimated Monetary Policy Rules." Contributions to Macroeconomics, 3(1), 2003, http://www.bepress.com/ bejm/contributions/vol3/iss1/art5.

Hamilton, James D. and Jorda, Oscar. "A Model of the Federal Funds Rate Target." Journal of Political Economy, October 2002, 110(5), pp. 1135-67.

Judd, John P. and Rudebusch, Glenn D. “Taylor's Rule and the Fed: 1970-1997." Federal Reserve Bank of San Francisco Review, 1998, (3), pp. 3-16.

Lubik, Thomas A. and Schorfheide, Frank. "Testing for Indeterminacy: An Application to U.S. Monetary Policy." American Economic Review, March 2004, 94(1), pp. 190-217.

Orphanides, Athanasios. "Monetary Policy Rules Based on Real-Time Data." American Economic Review, September 2001, 91(4), pp. 964-85.

Rudebusch, Glenn D. "Term Structure Evidence on Interest Rate Smoothing and Monetary Policy Inertia." Journal of Monetary Economics, September 2002, 49(6), pp. 1161-87.

Sack, Brian. "Does the Fed Act Gradually? A VAR Analysis." Journal of Monetary Economics, August 2000, 46(1), pp. 229-56.

Taylor, John B. "Discretion versus Policy Rules in Practice." Carnegie-Rochester Conference Series on Public Policy, December 1993, 39, pp. 195-214.

Woodford, Michael. "Optimal Interest-Rate Smoothing." Review of Economic Studies, October 2003, 70(4), pp. 861-86. 